\title{
Multimerin Is Found in the $\alpha$-Granules of Resting Platelets and Is Synthesized by a Megakaryocytic Cell Line
}

\author{
Catherine P. M. Hayward, Dorothy F. Bainton, James W. Smith, Peter Horsewood, Ron H. Stead, Thomas J. Podor, \\ Theodore E. Warkentin, and John G. Kelton \\ Departments of Medicine and Pathology, McMaster University Medical Centre, Hamilton, Canada L8N 325; the Canadian Red Cross \\ Blood Transfusion Service, Hamilton Centre, Canada L8N 1H8; and the Department of Pathology, University of California \\ School of Medicine, San Francisco, California 94143
}

\begin{abstract}
In this report, we describe the intracellular localization of multimerin in platelets and its biosynthesis by Dami cells, a megakaryocytic cell line. Immunoelectron microscopy was used to examine frozen thin sections of resting and activated platelets. Multimerin was localized within the platelet $\alpha$-granule in an eccentric position. Within activated platelets, multimerin was found in the surface-connected open cannalicular system and on the external plasma membrane. Light microscopic immunocytochemistry demonstrated multimerin in normal megakaryocytes and in Dami cells after stimulation with PMA. Confirmation of multimerin biosynthesis by Dami cells was obtained by metabolic labeling studies. Both platelet and Dami cell multimerin demonstrated several subunit sizes on reduced SDS-PAGE. However, peptide mapping confirmed structural homology between the different multimerin subunits. Glycosidase digestion demonstrated that multimerin is heavily glycosylated with mainly complex, $\mathbf{N}$-linked carbohydrate. In contrast to the multimerin isolated from platelets, cultured Dami cells secreted mainly smaller multimers of the protein. Biosynthesis of multimerin by a megakaryocytic cell line supports endogenous biosynthesis by megakaryocytes as the origin of this platelet $\alpha$ granule protein. (J. Clin. Invest. 1993. 91:2630-2639.) Key words: Dami cell • multimer • von Willebrand factor • bone marrow • immunocytochemistry
\end{abstract}

\section{Introduction}

Multimerin is an extremely large, soluble platelet glycoprotein that is expressed on the surface of activated platelets $(1,2)$. This protein exists as variably sized multimers that range from $<450 \mathrm{kD}$ to many million daltons $(1,2)$. Multimerin and von Willebrand factor share a similar complex multimeric composition and our previous studies demonstrated that multimerin and von Willebrand factor are the two largest proteins in platelets (2). The individual multimers of platelet multimerin are comprised of p-155 and p-170 subunits, linked by disulfide bonds (2). During platelet activation, multimerin moves from the platelet interior and becomes expressed on the platelet sur-

Address correspondence to John G. Kelton, Room 2N34, McMaster University Medical Centre, 1200 Main Street West, Hamilton, Ontario, Canada L8N $3 Z 5$.

Received for publication 11 June 1992 and in revised form 21 January 1993.

J. Clin. Invest.

(c) The American Society for Clinical Investigation, Inc. $0021-9738 / 93 / 06 / 2630 / 10 \$ 2.00$

Volume 91, June 1993, 2630-2639 face (1). The largest multimers of this protein remain bound to the platelet surface after activation and the smaller multimers are released (2).

The intent of the current study was to investigate the location and origin of platelet multimerin. Soluble proteins contained within platelets can originate from two sources: endogenous biosynthesis by megakaryocytes or endocytosis from plasma (3). In general, proteins synthesized by the megakaryocyte are present at a higher concentration in platelets than in plasma, whereas plasma-derived platelet proteins are present at a greater concentration in plasma than in platelets. Fibrinogen is the only known exception (3). Because we failed to detect multimerin in plasma, we postulated that this protein might be synthesized by megakaryocytes and stored within platelet granules for release upon activation. In this report, we describe the intracellular location of multimerin in platelets. Additionally, we demonstrate the presence of multimerin in normal megakaryocytes and its biosynthesis by Dami cells (4), a malignant megakaryocytic cell line.

\section{Methods}

Antibodies. Monoclonal antibody JS-1 and polyclonal rabbit antibodies against multimerin were used for immunoprecipitation and immunohistochemistry (1). Immunocytochemistry studies were performed using polyclonal antimultimerin and both monoclonal and polyclonal antibodies to von Willebrand factor (Dako Corp., Carpinteria, CA). These polyclonal antisera to multimerin and von Willebrand factor are non-cross-reactive and recognize reduced platelet proteins of 155 and $220 \mathrm{kD}$, respectively $(1,2)$. Additionally, using immunoblot studies, the polyclonal anti-von Willebrand factor does not recognize purified multimerin (1) and polyclonal antibodies to multimerin do not react with purified von Willebrand factor.

Platelet preparation. Washed platelets $\left(1 \times 10^{8} / \mathrm{ml}\right)$ were activated, without agitation, using bovine thrombin $(1 \mathrm{U} / \mathrm{ml}$; Sigma Immunochemicals, St. Louis, MO). After $10 \mathrm{~min}$, recombinant hirudin (Sigma), $4 \mathrm{U} / \mathrm{ml}$, was added. Activated platelets $\left(1 \times 10^{9} / \mathrm{ml}\right)$ were surface radiolabeled using ${ }^{125} \mathrm{I}$ and lactoperoxidase, washed, lysed, and used for immunoprecipitation $(1,5)$.

Dami cell preparation. Dami cells (4) were a generous gift of Dr. Sheryl M. Greenberg, Hematology Division, Brigham and Women's Hospital, Boston, MA. The cells were obtained from the American Type Culture Collection (CRL 9792), Rockville, MD. Cells were grown in RPMI 1640 medium supplemented with $5 \%$ fetal calf serum, $10 \mathrm{mM}$ sodium bicarbonate, $10 \mathrm{mM}$ Hepes, and $2 \mathrm{mM}$ glutamine. For some experiments, Dami cells were activated by incubating the cells with 5 nM PMA. Cytochemistry studies were performed on Dami cells that were cultured on glass coverslips.

Dami cells $\left(5 \times 10^{5} / \mathrm{ml}\right)$ were surface labeled with ${ }^{125} \mathrm{I}(1,5)$, washed, and solubilized in lysing buffer containing proteolytic inhibitors ( $1 \%$ Triton X-100, $0.1 \%$ SDS, $20 \mathrm{mM}$ Tris, $100 \mathrm{mM} \mathrm{NaCl}$, pH 7.4, with $10 \mathrm{mM}$ EDTA, $0.1 \mu \mathrm{M}$ leupeptin, $0.2 \mathrm{mM}$ PMSF, $0.02 \mathrm{mg} /$ liter soybean trypsin inhibitor, and $5 \mathrm{mM} \mathrm{N}$-ethyl maleimide; $1 \times 10^{5}$ cells $/ \mathrm{ml})$. 
Metabolic labeling was performed using $\left[{ }^{35}\right.$ S]methionine (NEN/ Dupont Canada Inc., Mississauga, Canada) in methionine-free medium. For 18-h labeling studies, $5 \mathrm{ml}$ vol of medium containing 0.1 $\mathrm{mCi} / \mathrm{ml}$ of $\left[{ }^{35} \mathrm{~S}\right]$ methionine were used. For pulse-chase experiments, 1 $\mathrm{ml}$ of culture medium containing $0.5 \mathrm{mCi}$ of ${ }^{35} \mathrm{~S}$ methionine was used.

Cleveland mapping of the Dami cell multimerin was performed using supernatant from an 18-h labeling with Trans ${ }^{35} \mathrm{~S}$-label $(0.5 \mathrm{mCi} /$ $5 \mathrm{ml}$; ICN Biomedicals Canada, Ltd., Montreal, Canada) and methionine-free, cysteine-free media. For some experiments, tunicamycin ( 1 $\mu \mathrm{g} / \mathrm{ml}$; Boehringer Mannheim Canada, Laval, Quebec) was added to culture medium $3 \mathrm{~h}$ before labeling. The labeled Dami cells were solubilized in lysing buffer to the same final volume as the culture supernatant $\left(\sim 1 \times 10^{5}\right.$ cells $\left./ \mathrm{ml}\right)$.

Immunocytochemistry. Resting platelets and thrombin stimulated ( $2 \mathrm{U} / 10^{9}$ platelets in Tyrode's buffer containing $1 \mathrm{mM}$ calcium, $5 \mathrm{~min}$, $37^{\circ} \mathrm{C}$.) platelets were fixed in $4 \%$ paraformaldehyde in $0.1 \mathrm{M}$ phosphate buffer, $\mathrm{pH} 7.4$ for $3 \mathrm{~h}$ at $4^{\circ} \mathrm{C}$. Cells were embedded in $2.3 \mathrm{M}$ sucrose and frozen thin sections were cut from the cell block. Immunocytochemistry was performed as described $(6,7)$ using polyclonal rabbit antimultimerin (1:50) and goat anti-rabbit gold-10 (Amersham Corp., Arlington Heights, IL). A double-labeling experiment to localize multimerin and von Willebrand factor was performed using protein $A$, as described by Slot and Geuze (8). Rabbit antibody against multimerin was applied (dilution 1:10) and labeled with protein A-10. Before the addition of the second antibody, free protein $A(0.05 \mathrm{mg} / \mathrm{ml})$ was applied. Subsequently, rabbit antibodies to von Willebrand factor were added at a 1:10 dilution followed by protein A-5. A second experiment was also performed using the polyclonal multimerin antibody and goat anti-rabbit gold-5 and a monoclonal antibody against von Willebrand's factor (dilution 1:10) and goat anti-mouse gold. Controls consisted of a primary incubation with normal rabbit serum.

Immunocytochemistry was performed on normal bone marrow smears and on resting and PMA-activated Dami cells. Air-dried smears were fixed in acetone at $4^{\circ} \mathrm{C}$ for $15 \mathrm{~min}$ before blocking endogenous peroxidase activity with $0.5 \%$ hydrogen peroxide in methanol for 20 min. After further air drying, the slides were rinsed in Tris-buffered saline, pH 7.6 (TBS) ${ }^{1}$ and incubated for $1 \mathrm{~h}$ in TBS with JS-1 (monoclonal antimultimerin; 1:100-1:1,000 dilution ) or TBS alone (negative control). The slides were rinsed in TBS and incubated in biotinylated rabbit anti-mouse immunoglobulins ( $10 \mathrm{~min}$ ) and streptavidin peroxidase conjugate ( $5 \mathrm{~min}$; Histostain SP kit; Zymed Laboratories Inc., South San Francisco, CA). Peroxidase was demonstrated using aminoethylcarbazole in acetate buffer, pH 5.0. Nuclei were counterstained with hematoxylin.

Radioimmunoprecipitation. Immunoprecipitations of 1-ml vol of radiolabeled cell lysates or culture supernatant were performed using protein A sepharose beads ( $50 \mu \mathrm{l})$ and either monoclonal ( $10 \mu \mathrm{l} \mathrm{JS}-1)$ or polyclonal antibodies $(50 \mu \mathrm{l})$ against multimerin $(1)$. To reduce nonspecific binding, samples from 18 -h metabolic labeling experiments were subjected to two consecutive immunoprecipitations (9), using polyclonal antimultimerin. Beads were washed five times with lysing buffer (containing $0.2 \%$ Triton X-100), eluted with $100 \mu \mathrm{l}$ of lysing buffer containing $2 \%$ SDS, $2 \%$ Triton $X-100$, and $2 \%$ sodium deoxycholate, and boiled. Eluates were collected, diluted 10-fold with lysing buffer (containing $0.2 \%$ Triton X-100) and a second immunoprecipitation was performed. Immunoprecipitates were used for subunit and multimer analyses $(1,2)$. For pulse-chase experiments, single immunoprecipitations were performed using polyclonal antimultimerin.

Subunit analysis. Immunoprecipitates were analyzed by reduced SDS-PAGE and autoradiography or fluorography (1).

Multimer analysis. Immunoprecipitates were eluted with agarose/ acrylamide sample buffer (final concentrations: $10 \mathrm{mM}$ Tris, $2 \%$ SDS, $8 \mathrm{M}$ urea, $0.005 \%$ bromophenol blue; $\mathrm{pH} 8.0$ ). Samples were analyzed by nonreduced, agarose/acrylamide gel electrophoresis using $1.25 \%$

1. Abbreviation used in this paper: TBS, Tris-buffered saline. agarose gels (SeaPlaque agarose; FMC Corp., FMC BioProducts, Rockland, ME) containing $1.5 \%$ acrylamide (2). Thrombospondin was used as a reference for multimer size (2). Individual multimer subunit composition was assessed by two-dimensional, nonreduced/ reduced electrophoresis as described (2).

Protease mapping. Cleveland mapping was used to compare the different multimerin subunits (10). Multimerin immunoprecipitates were prepared, reduced, and alkylated (1), followed by subunit separation using SDS-PAGE. The radiolabeled proteins were isolated from dried gels and protease digestion was performed in the stacking gel using V8 protease $(0.05,0.1,0.5$, and $5.0 \mu \mathrm{g} /$ lane $)$, chymotrypsin ( 1 , 10 , and $50 \mu \mathrm{g} /$ lane $)$ and trypsin $(1,10$, and $50 \mu \mathrm{g} /$ lane $)$. Peptides were resolved using $7-15 \%$ SDS-PAGE.

Carbohydrate analysis. The carbohydrate content of multimerin was assessed by exo and endoglycosidase digestions $(9,11)$. Multimerin immunoprecipitates were eluted with $0.1 \%$ SDS, $0.2 \% 2$-mercaptoethanol containing protease inhibitors (final concentrations: 0.1 $\mathrm{mg} / \mathrm{ml}$ benzaminidine, $1 \mathrm{mM}$ PMSF, $1 \mu \mathrm{g} / \mathrm{ml}$ aprotonin, $10 \mu \mathrm{g} / \mathrm{ml}$ leupeptin). The test samples were incubated with the different glycosidases, then analyzed by reduced SDS-PAGE. To exclude proteolytic degradation during the glycosidase incubations, control samples were incubated in buffer without glycosidase. Glycosidases used included: endoglycosidase $\mathrm{H}$ (Boehringer Mannheim; final concentrations: 50 $\mathrm{mU} / \mathrm{ml}$ in $100 \mathrm{mM}$ sodium phosphate buffer, $\mathrm{pH} 6.0,18 \mathrm{~h}, 37^{\circ} \mathrm{C}$ ), endoglycosidase $\mathrm{F} / N$-glycosidase $\mathrm{F}$-free and endoglycosidase $\mathrm{F} / \mathrm{N}$-glycosidase $\mathrm{F}$ ( Boehringer Mannheim, for both glycosidases, final concen-

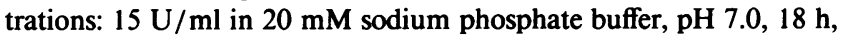
$37^{\circ} \mathrm{C}$ ), neuraminidase (Boehringer Mannheim, final concentrations: 2 $\mathrm{U} / \mathrm{ml}$ in $20 \mathrm{mM}$ sodium acetate buffer, $\mathrm{pH} 5.5,1 \mathrm{~h}, 37^{\circ} \mathrm{C}$ ) and $O$-glycanase (Genzyme Corp., Cambridge, MA; final concentrations: 30 $\mathrm{mU} / \mathrm{ml}$ added to the neuraminidase treated protein, $5 \mathrm{~h}, 37^{\circ} \mathrm{C}$ ). After incubation with the glycosidase, $100 \mu \mathrm{l}$ of $2 \times$ reducing sample buffer was added to all tubes, followed by reduced SDS-PAGE. For some studies, both $\mathrm{N}$ - and $\mathrm{O}$-linked carbohydrates were removed by treating the immunoprecipitates with $\mathrm{N}$-glycosidase $\mathrm{F}$ followed by neuraminidase and $O$-glycanase.

\section{Results}

Intracellular localization of multimerin in platelets. Immunoelectron microscopy performed on frozen thin sections of platelets demonstrated the presence of multimerin in an eccentric position within the $\alpha$-granule of resting platelets (Fig. 1, $a$ and $b$ ). Only small amounts of multimerin were detected on the plasma membrane of resting platelets. Using double labeling experiments with antibodies (either monoclonal or polyclonal) to von Willebrand factor and multimerin and two different sizes of gold, multimerin and von Willebrand factor colocalized to the same region of the $\alpha$-granule (Fig. $1 a$, inset panel, and $b$ ). No labeling of $\alpha$-granules was observed in the negative controls.

Studies performed on frozen thin sections of thrombin-activated platelets demonstrated that the multimerin was located on the external plasma membrane and within the surface-connected cannalicular system after platelet activation (Fig. $1 c$ ). There was no significant labeling of the surface-connected cannalicular system or plasma membrane in the negative controls.

Demonstration of multimerin in megakaryocytes and in Dami cells. Normal bone marrow megakaryocytes and resting and PMA-activated Dami cells were examined using immunocytochemical techniques and the monoclonal antibody to multimerin (Fig. 2). Normal megakaryocytes and platelets stained intensely for multimerin in a granular pattern. Other bone marrow cells were not multimerin immunoreactive. While we did not detect the presence of multimerin in resting Dami cells, 

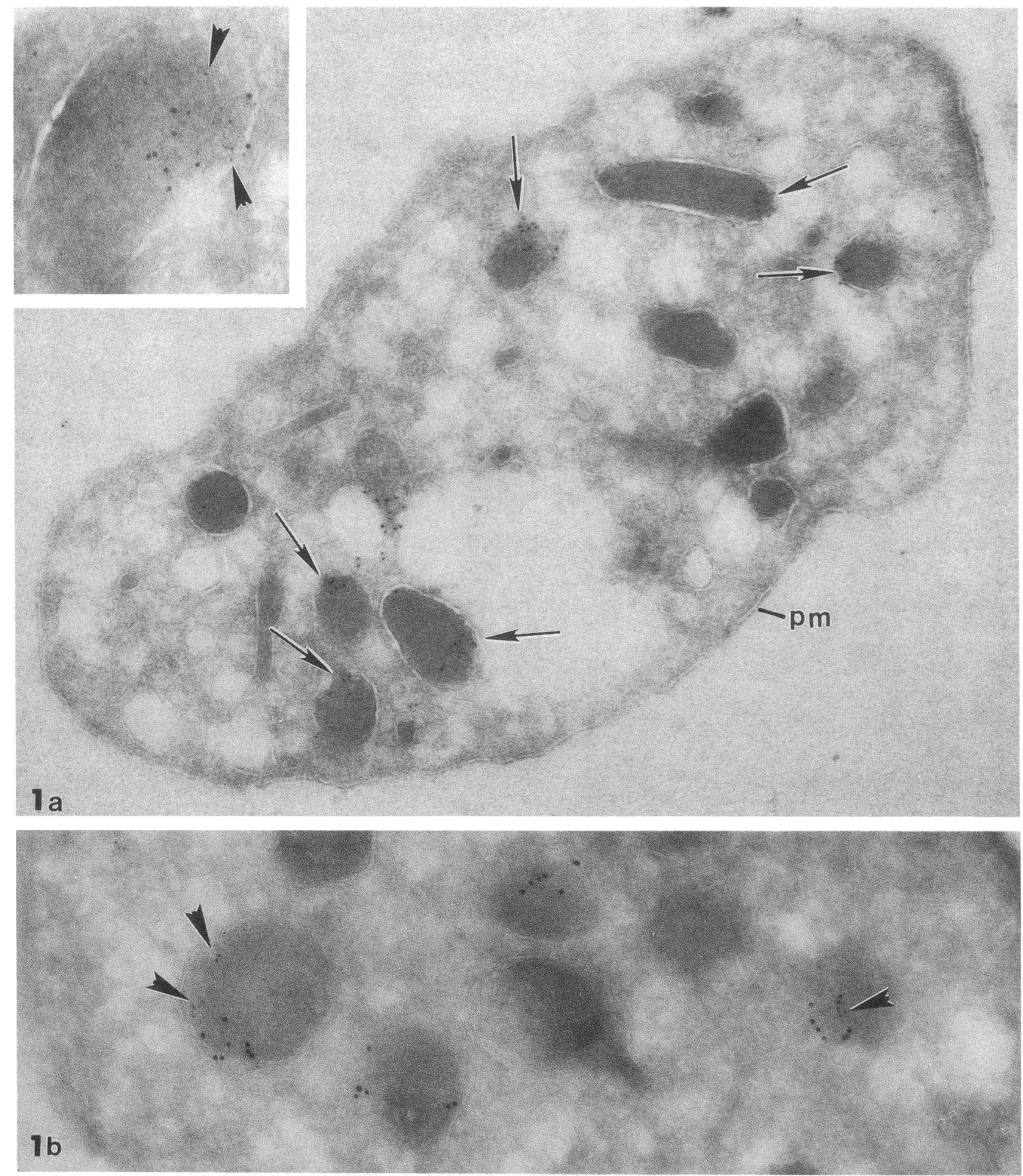

Figure 1. Immunogold labeling of multimerin in frozen thin sections of resting and activated platelets. In resting platelets, labeled using polyclonal antibodies to multimerin and goat anti-rabbit gold-10 (panel $a, \times 50,000$ ), the gold particles were found within the alpha granule matrix, usually in an eccentric position (large arrows). Rare label was detected on the plasma membrane ( pm). Double labeling studies of resting platelets (inset of an alpha granule, panel $a, \times 98,000$ ) were performed using polyclonal antibodies to multimerin (detection with protein A gold-10) and to von Willebrand factor (detection with protein A gold-5; small arrows). Multimerin (the large gold) and von Willebrand factor (the small gold) colocalized to the same region of the alpha granules. In panel $b(\times 60,000)$, von Willebrand factor was detected with a monoclonal antibody and goat anti-mouse gold-10, and multimerin was detected with a polyclonal antibody and goat anti-rabbit gold-5. The results are similar to panel $a$, and short arrows point to the granules with eccentric double-labeling.

Thrombin-stimulated platelets (panel $c, \times 42,000$ ) exhibited shape change and aggregation. Immunocytochemistry using polyclonal antibodies to multimerin and goat anti-rabbit gold-10 demonstrated presence of gold in large vacuoles $(v)$ many of which are probably sections of the surface-connected cannalicular system. Smaller amounts of the label were localized to the external plasma membrane. No label was detected in the tight "contact zones" $(C Z)$. 


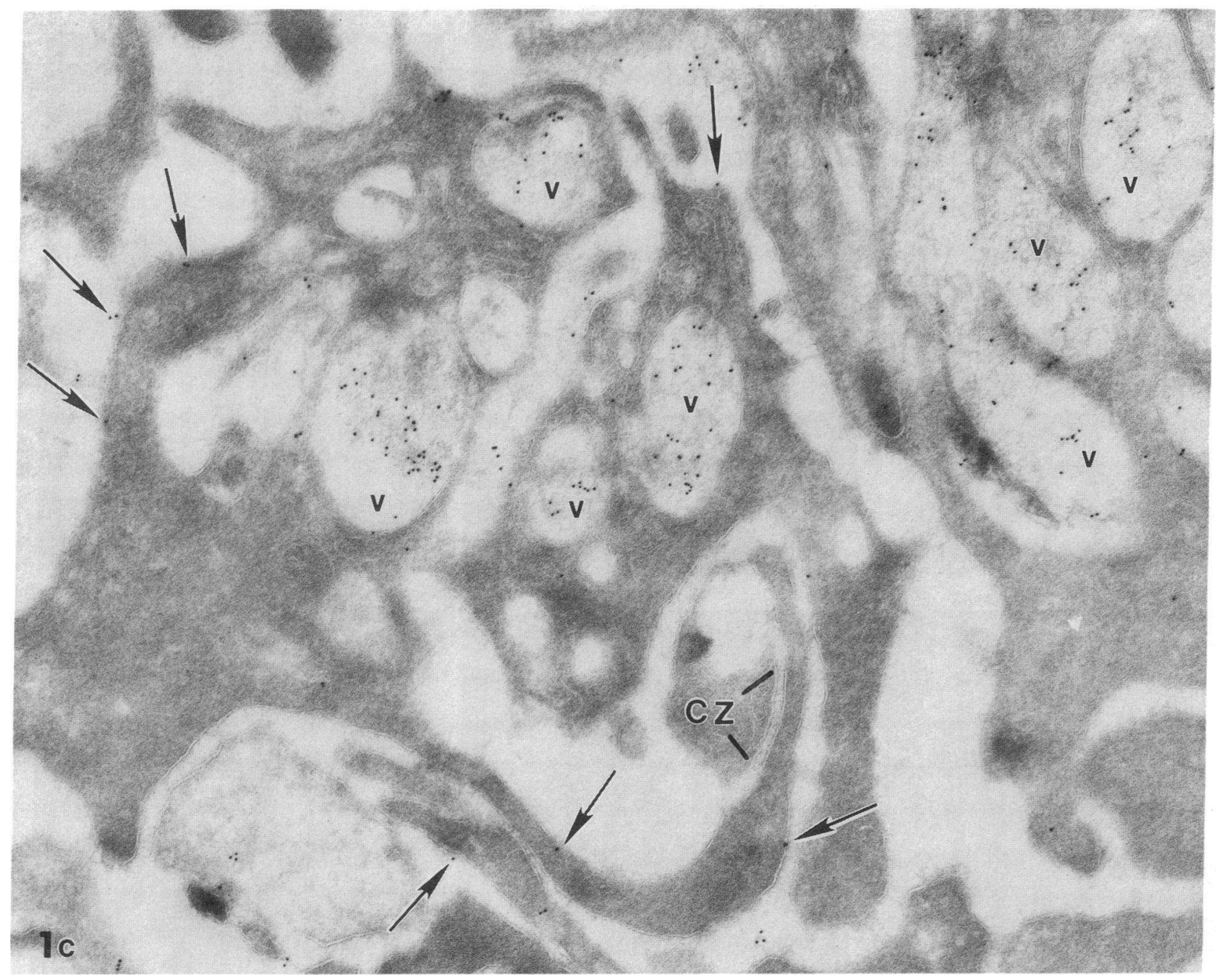

Figure 1 (Continued)

PMA-activated Dami cells showed a granular distribution of the protein. Background staining suggestive of an extracellular matrix distribution was observed for the PMA-activated Dami cells. Compared to the normal megakaryocytes, the PMA-activated Dami cells stained less intensely for multimerin. No staining was observed in the control slides processed without the monoclonal antibody.

To determine if endogenous biosynthesis was the source of multimerin in Dami cells, metabolic labeling studies were performed. Untreated and PMA-stimulated cells were metabolically labeled ( $18 \mathrm{~h},\left[{ }^{35} \mathrm{~S}\right]$ methionine) during the $1 \mathrm{st}, 2 \mathrm{nd}$, and 3rd day of PMA stimulation. Multimerin immunoprecipitates were prepared from culture supernatants and cell lysates. Multimerin was not detected in the cell lysate or culture supernatant of resting Dami cells (Fig. 3). After stimulation with PMA, Dami cells synthesized and secreted multimerin. After 1 d of PMA stimulation, multimerin was detected both in the Dami cell lysate and culture supernatant and continued to be synthesized and secreted over the next several days of PMA stimulation. Greater quantities of multimerin were present in the culture supernatant compared to the cell lysate, indicating that the majority of the protein was secreted. Multimerin was not detected on the surface of resuspended, washed, PMAstimulated Dami cells (Fig. 3).

When the intracellular and secreted multimerin from an 18-h metabolic labeling were compared, the proteins differed in their reduced subunit size. The $170-\mathrm{kD}$ band was the predominant protein in the cell lysate (Fig. 3). The secreted protein was comprised of $196-$ and $165-\mathrm{kD}$ subunits, with a greater proportion of the larger subunit (Fig. 3). Both monoclonal and polyclonal antibodies to multimerin immunoprecipitated the two protein subunits from the culture supernatant. Comparison of the Dami cell multimerin with the platelet multimerin subunit revealed that the protein synthesized and secreted by the Dami cells had a larger subunit size (reduced) than the mature platelet protein.

Cleveland mapping of multimerin subunits. Cleveland mapping was used to investigate if the different subunits present in the reduced multimerin immunoprecipitates originated from a common precursor protein. Protease digestion of platelet p-155 and p-170 generated identical peptides (Fig. 4). Trypsin, chymotrypsin, and V8 protease digests showed extensive, but not complete, peptide homology between the $\mathrm{p}-155$ platelet multimerin subunit and the p-196 Dami cell multimerin sub- 

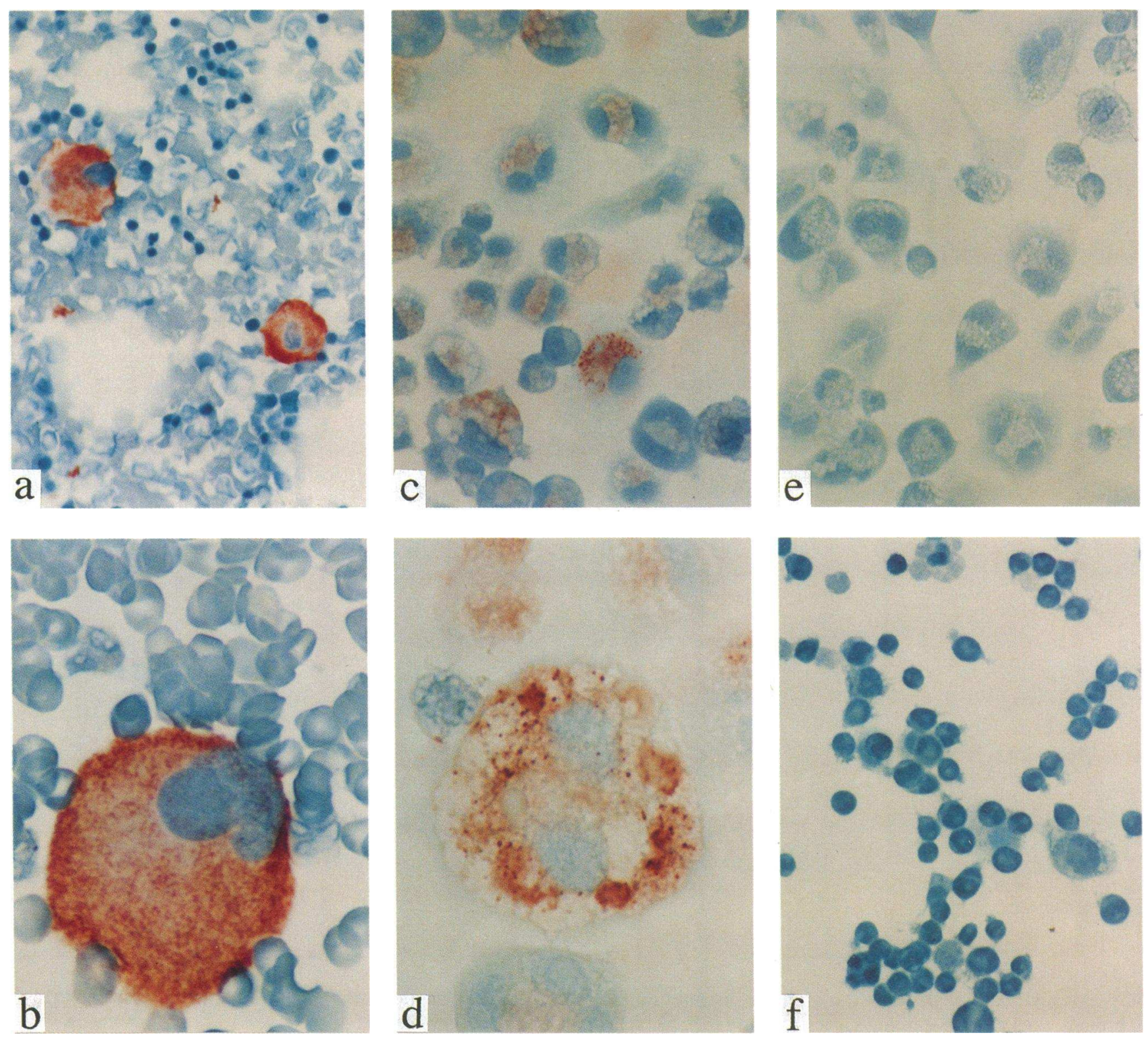

Figure 2. Immunocytochemistry demonstrating multimerin in megakaryocytes and in Dami cells. Immunocytochemistry was performed on normal bone marrow and on resting and PMA-stimulated Dami cells using JS-1 (monoclonal antimultimerin). Normal megakaryocytes exhibited intense staining for multimerin with a granular distribution (panel $a, \times 320$; panel $b, \times 800$ ). Only megakaryocytes and platelets were labeled. Resting Dami cells did not exhibit any staining with antibodies to multimerin (panel $f, \times 320$ ); however, after PMA stimulation, multimerin was evident in Dami cells (panel $c, \times 320$; panel $d, \times 800$ ). In most cells, a granular pattern of staining was observed with some evidence of extracellular staining, suggestive of a matrix distribution. Control slides, processed without JS-1, did not show any staining (panel $e, \times 320$ ).

unit (Fig. 4). The observed differences may be due to a longer peptide sequence in $\mathrm{p}-196$, differences in glycosylation between the protein synthesized in vivo and in vitro, or the distribution of the different radiolabels on the individual peptides.

Carbohydrate composition of multimerin. Glycosidase digestions were performed to determine the carbohydrate composition of multimerin and to further investigate the differences in subunit sizes (Fig. 5). The platelet p-155 and p-170 multimerin subunits contained similar quantities of $\mathrm{N}$-linked carbohydrate (Fig. 5, lane 4) and sialic acid (Fig. 5, lane 2). Removal of all $\mathrm{N}$-linked carbohydrate by $\mathrm{N}$-glycosidase $\mathrm{F}$ from p-170 and p- 155 resulted in proteins with mobilities of 120 and
$105 \mathrm{kD}$, respectively (Fig. 5, lane 4). Resistance of p-155 and p-170 to endoglycosidase $F$ and endoglycosidase $H$ (Fig. 5, lanes 6 and 11 ), indicated that p-155 and p-170 contain only the complex forms of $\mathrm{N}$-linked carbohydrate. In contrast to the results obtained using $\mathrm{N}$-glycosidase F, $O$-glycanase treatment resulted in only a minor shift in mobility of the $\mathrm{p}-155$ subunit (Fig. 5, lane 21). Together, these results demonstrate that p-155 and p-170 multimerin subunits are highly glycosylated proteins that contain mainly complex $\mathrm{N}$-linked carbohydrate. The failure of the deglycosylated subunits to comigrate (Fig. 5, lane 4) indicates that p-170 contains a larger polypeptide component than p-155. 


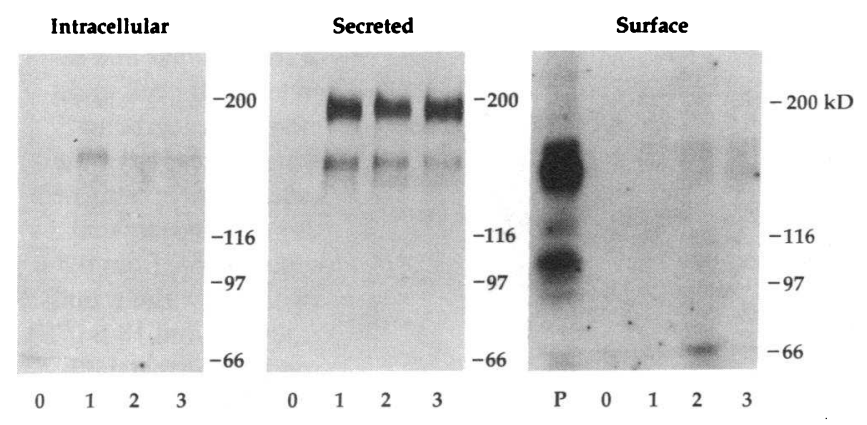

Figure 3. Dami cells synthesize multimerin after stimulation with PMA. Multimerin immunoprecipitates were prepared from ${ }^{125} \mathrm{I}$ surface radiolabeled Dami cells and $\left[{ }^{35} S\right]$ methionine metabolically labeled Dami cells. Cells were labeled during $0,1,2$, or $3 \mathrm{~d}$ (lanes designated $0,1,2,3$ ) of PMA stimulation. Samples were analyzed by SDS-PAGE. For comparison, the multimerin from surface radiolabeled, activated platelets is shown in lane $P$. This study demonstrates that Dami cells synthesize and secrete multimerin after stimulation with PMA. Compared to activated platelets, PMA-stimulated, resuspended Dami cells do not express detectable amounts of multimerin on their surface. Bands below $155 \mathrm{kD}$ in the platelet sample may represent coprecipitated proteins or degradation products.

Similar to platelet multimerin (Fig. 5, lane 15), the secreted Dami cell multimerin contained a large component of $\mathrm{N}$ linked carbohydrate, evidenced by large mobility shifts of the p-196 and p-165 subunits after treatment with endoglycosidase $\mathrm{F} / \mathrm{N}$-glycosidase $\mathrm{F}$ (Fig. 5, lane 16). Additionally, the secreted Dami cell multimerin was resistant to endoglycosidase F (Fig. 5 , lane 12) and to endoglycosidase $\mathrm{H}$ (Fig. 5, lane 10), indicating that, like platelet multimerin, all of the N-linked carbohydrate had been processed to complex forms. The Dami cell p-196 subunit migrated with an apparent reduced molecular mass of $145 \mathrm{kD}$ ( $5 \%$ polyacrylamide gels; Fig. 5, lane 16) after removal of N-linked carbohydrate. As observed with the deglycosylated subunits of platelet multimerin, the smaller p- 165 subunit of Dami cell multimerin contained a smaller polypeptide component than the larger p-196 subunit (Fig. 5, lane 16). Because the deglycosylated p-155 platelet multimerin subunit was smaller (Fig. 5, lane 15) than the deglycosylated subunits of multimerin from Dami cells (Fig. 5, lane 16), we postulate that there is more complete proteolytic processing of the protein derived from platelets.

The 196-kD Dami cell multimerin subunit contained sialic acid that was not completely removed by treatment with $\mathrm{N}$-glycanase $\mathrm{F}$ (Fig. 5, lanes 16 and 18 ), suggesting the presence of O-linked carbohydrate. $O$-glycanase digestion resulted in a 9$\mathrm{kD}$ mobility shift in the neuraminidase-treated $196-\mathrm{kD}$ subunit (Fig. 5, lanes 20 and 22), confirming the presence of O-linked sugars on the p-196 subunit of multimerin. However, complex, $\mathrm{N}$-linked carbohydrate is the predominant type.

Processing of multimerin during biosynthesis. Pulse-chase studies were undertaken to follow the processing of multimerin during its biosynthesis. Dami cells were metabolically labeled ( $20 \mathrm{~min}$ ) and biosynthesis was followed in the culture supernatants and cell lysates at varying chase intervals after pulse labeling (Fig. 6). This study demonstrated that the first multimerin subunit synthesized was $170 \mathrm{kD}$. Subsequently the $196-\mathrm{kD}$ protein became detectable in the cell lysate with the amount progressively increasing over the next hour. Secretion of the protein was first detected at $1 \mathrm{~h}$ and almost all of the synthe-
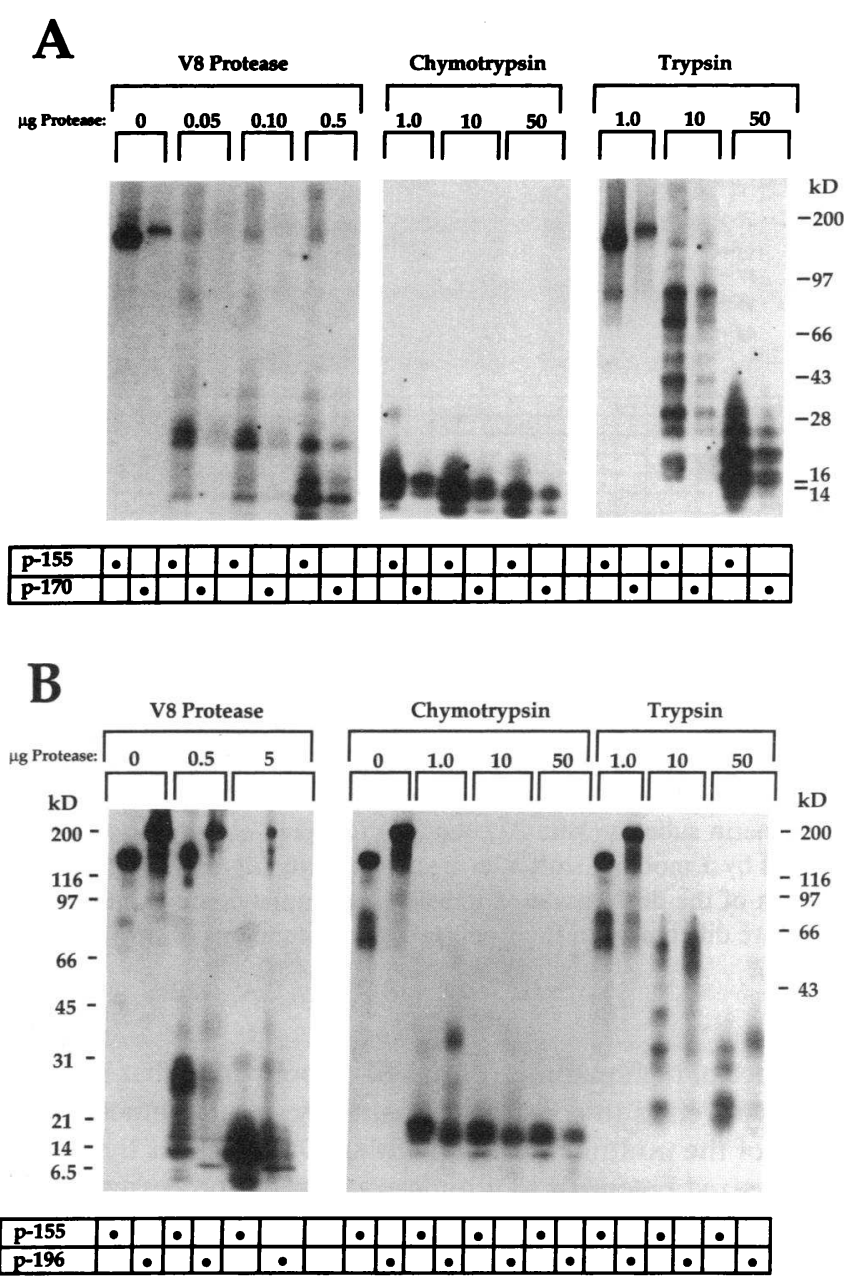

Figure 4. Peptide mapping of multimerin subunits. Multimerin immunoprecipitates prepared from ${ }^{125}$ I surface labeled, activated platelets and from the culture supernatant of $18-\mathrm{h}^{35} \mathrm{~S}$ metabolically labeled, day 2 PMA-stimulated Dami cells were used to isolate the subunit proteins. Peptide mapping was performed by the method of Cleveland using V8 protease $(0.05,0.1,0.5$, and $5.0 \mu \mathrm{g} /$ lane $)$, chymotrypsin $(1,10$, and $50 \mu \mathrm{g} /$ lane $)$ and trypsin $(1,10$, and $50 \mu \mathrm{g} /$ lane). $(A)$ Comparison of platelet $\mathrm{p}-155$ and $\mathrm{p}-170$ multimerin subunits. This study demonstrates that the platelet multimerin subunits are highly related proteins with complete peptide homology. $(B)$ Comparison of platelet p-155 and Dami cell p-196 multimerin subunits. This study demonstrates extensive peptide homology between the platelet p-155 and the larger Dami cell p-196.

sized multimerin was secreted within $3 \mathrm{~h}$ of biosynthesis. The secreted multimerin was primarily the $196-\mathrm{kD}$ protein with smaller amounts of the $165-\mathrm{kD}$ subunit.

We postulated that the increase in the molecular weight of multimerin subunit during biosynthesis was due to the addition of carbohydrate. Additionally, because the pulse-chase studies indicated rapid secretion, we postulated that the intracellular multimerin from 18 -h labeling experiments was mainly the recently synthesized, precursor form of the protein. To address these issues, the multimerin prepared from 18-h metabolic labeled Dami cell lysate was compared to the precursor protein synthesized during a 0.5 -h metabolic labeling (Fig. $7 a$ ). Both lysates contained a $170-\mathrm{kD}$ multimerin subunit that was susceptible to endoglycosidase $\mathrm{H}$ digestion, indicating the 


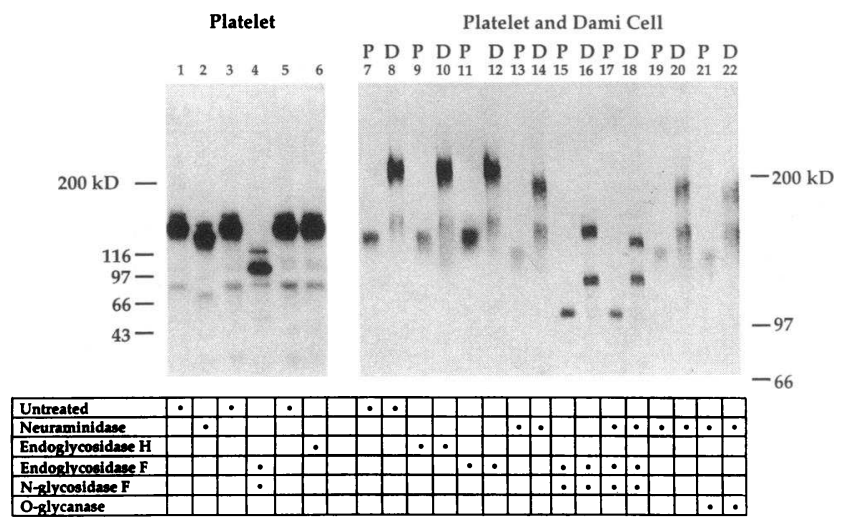

Figure 5. The carbohydrate composition of multimerin. The carbohydrate composition of platelet and Dami cell multimerin was assessed by digestion with endo and exoglycosidases. Platelet multimerin subunits were analyzed by 4-8\% SDS-PAGE (lanes 1-6) and $5 \%$ SDS-PAGE was used to compare the Dami cell $(D)$ and platelet $(P)$ multimerin subunits (lanes 7-22). Both platelet (lanes 4 and 15) and Dami cell (lane 16) multimerin subunits are highly glycosylated with mainly complex, N-linked carbohydrate. The Dami cell p-196 multimerin subunit (lane 22) contains O-linked carbohydrate, evidenced by a mobility shift after treatment with $O$-glycanase. Comparison of the deglycosylated individual subunits demonstrates that there are differences in their polypeptide components (lanes 4 and 15-22).

presence of high mannose $\mathrm{N}$-linked carbohydrate that had not been converted to complex forms. These results indicate that most of the multimerin found within Dami cells is the newly synthesized precursor that undergoes further processing of $\mathrm{N}$ linked carbohydrate before secretion of the mature subunits.

Prevention of $\mathrm{N}$-glycosylation in Dami cells with tunicamycin resulted in the biosynthesis of a smaller precursor pro-

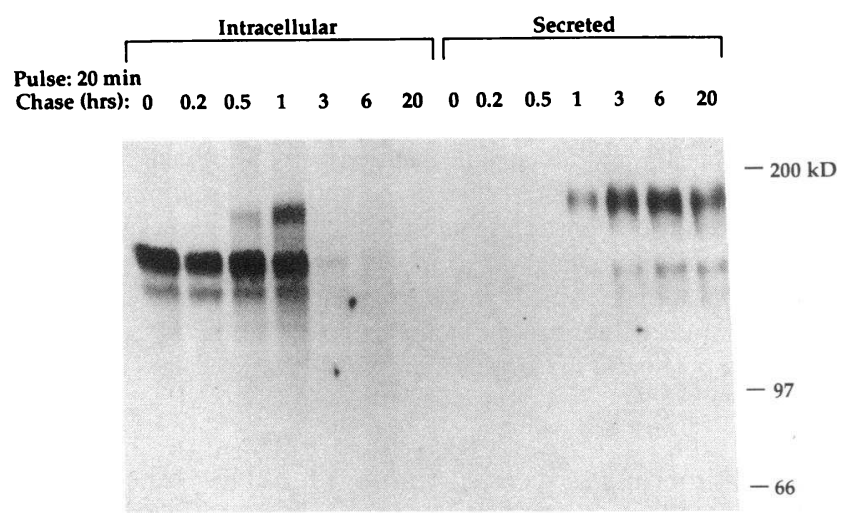

Figure 6. Pulse-chase study of multimerin biosynthesis by Dami cells. Day 2, PMA-stimulated Dami cells were pulse labeled for $20 \mathrm{~min}$ with $\left[{ }^{35} \mathrm{~S}\right]$ methionine. Multimerin immunoprecipitates were prepared from cell lysates and supernatants collected at $0,0.2,0.5,1,3$, 6 , and $20 \mathrm{~h}$ after pulse and analyzed by SDS-PAGE. This study demonstrates that multimerin is synthesized as a $170-\mathrm{kD}$ subunit, followed by further processing to generate the secreted 196- and 165-kD subunits. The larger 196-kD subunit first appears in the cell lysate at $0.5 \mathrm{~h}$ and its appearance is rapidly followed by secretion of 196and $165-\mathrm{kD}$ subunits. Almost all of the synthesized protein was secreted by $3 \mathrm{~h}$. The band at $140 \mathrm{kD}$ in the cell lysate was not consistently seen in other pulse chase experiments and may represent a coprecipitated protein.
$\mathbf{A}$

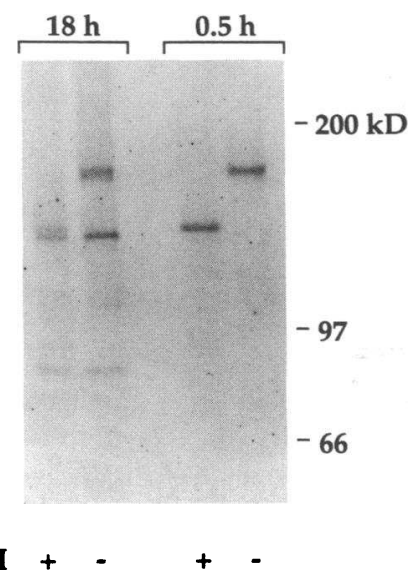

B

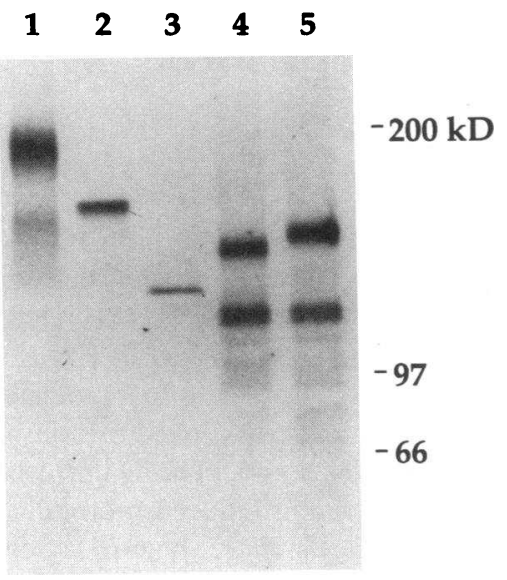

S I $\quad$ I $\quad \mathbf{S} \quad \mathbf{S}$
Figure 7. Comparison of intracellular and secreted Dami cell multimerin. The carbohydrate processing of multimerin was investigated using cell lysates and supernatants from $0.5 \mathrm{~h}$ (with and without tunicamycin ) and $18-\mathrm{h}\left[{ }^{35} \mathrm{~S}\right]-$ methionine metabolically labeled, day 2 PMA-stimulated Dami cells. Immunoprecipitates were incubated with glycosidases or buffer, followed by reduced 5\% SDS-PAGE (A) The $170-\mathrm{kD}$ intracellular multimerin subunit from an 18-h labeling study comigrated with the multimerin precursor synthesized during a 0.5-h labeling. Both proteins contained endoglycosidase $\mathrm{H}$ sensitive, high mannose $\mathrm{N}$ linked carbohydrate. These findings indicate that the multimerin contained in the 18-h cell lysate is the recently synthesized, precursor form of multimerin. The multimerin immunoprecipitate from the 18-h lysate contained an additional endoglycosidase $\mathrm{H}$ resistant $130-\mathrm{kD}$ protein

not seen in previous 18 -h lysates (Fig. 3). This may represent a coprecipitated protein. $(B)$ The carbohydrate composition of the intracellular $(I)$ and secreted $(S)$ multimerin subunits were compared. The mature secreted protein consists of 196 and $165 \mathrm{kD}$ subunits (lane 1,18 -h labeling) in contrast to the intracellular $170-\mathrm{kD}$ subunit (lane 2, 0.5-h labeling). Prevention of $\mathrm{N}$-glycosylation with tunicamycin resulted in the synthesis of a $132-\mathrm{kD}$ protein (lane $3,0.5-\mathrm{h}$ labeling) that did not comigrate with either of the $\mathrm{N}$-glycosidase F-treated, secreted subunits of multimerin (lane 5,18 -h labeling). Neuraminidase treatment further reduced the $M_{\mathrm{r}}$ of the N-deglycosylated, secreted multimerin (lane 4, 18-h labeling), indicating the presence of non- $\mathrm{N}$-linked carbohydrate on the secreted $196-\mathrm{kD}$ subunit.

This study demonstrates that formation of the mature, secreted protein involves conversion of high mannose $\mathrm{N}$-linked carbohydrate to complex forms, the addition of O-linked carbohydrate and also indicates that proteolysis is required to generate the $165-\mathrm{kD}$ subunit.

tein that migrated at $132 \mathrm{kD}$ (Fig. $7 b$, lane 3 ) in contrast to the $170-\mathrm{kD}$ protein synthesized in the absence of tunicamycin (Fig. $7 b$, lane 2 ). The endoglycosidase $\mathrm{H}$ treatment of the early precursor protein resulted in an equivalent reduction in apparent $M_{\mathrm{r}}$ (Fig. $7 a$ ), suggesting that the $170-\mathrm{kD}$ multimerin precursor contained only high mannose forms of $\mathrm{N}$-linked carbohydrate. 
Further studies were performed to investigate O-glycosylation during the biosynthesis of multimerin. The presence of O-linked carbohydrate was suggested by the higher $M_{\mathrm{r}}$ of the N-deglycosylated, 196-kD secreted multimerin subunit (Fig. 7 $b$, lane 5 ), compared with the $132-\mathrm{kD}$ protein synthesized in the presence of tunicamycin (Fig. $7 b$, lane 3 ). The presence of O-linked carbohydrate was confirmed by demonstrating that neuraminidase reduced the $M_{\mathrm{r}}$ of the N-deglycosylated p-196 (Fig. $7 b$, lane 4; Fig. 5, lane 18) and $O$-glycanase further reduced the $M_{\mathrm{r}}$ of p-196 (Fig. 5, lane 22). The N-deglycosylated, secreted p-165 was smaller than the precursor protein synthesized in the presence of tunicamycin (Fig. $7 b$, lanes 5 and 3 ), indicating that production of the smaller subunit of the secreted protein requires proteolysis. The observed differences in migration of the Dami cell p-165 and platelet p-170 multimerin subunits may reflect differences in either glycosylation or proteolysis.

Because the megakaryocytic cell line synthesized a larger multimerin subunit than found in platelets, we looked for evidence that the multimerin contained within platelets had originated from a larger precursor protein. A $200-\mathrm{kD}$ band was occasionally observed in reduced multimerin immunoprecipitates from surface-labeled thrombin-activated platelets. To determine if this protein was a component of multimerin, two-dimensional nonreduced/reduced electrophoresis was performed. The $200-\mathrm{kD}$ protein was present within the multimerin multimers, covalently linked to the p-155 and p-170 subunits by interchain disulfide bonds (Fig. 8).

Comparison of the multimeric composition of platelet multimerin and the multimerin secreted by Dami cells. Agarose/ acrylamide gels were used to investigate the nonreduced structure of multimerin synthesized by Dami cells. Multimerin im-

\section{Platelets}

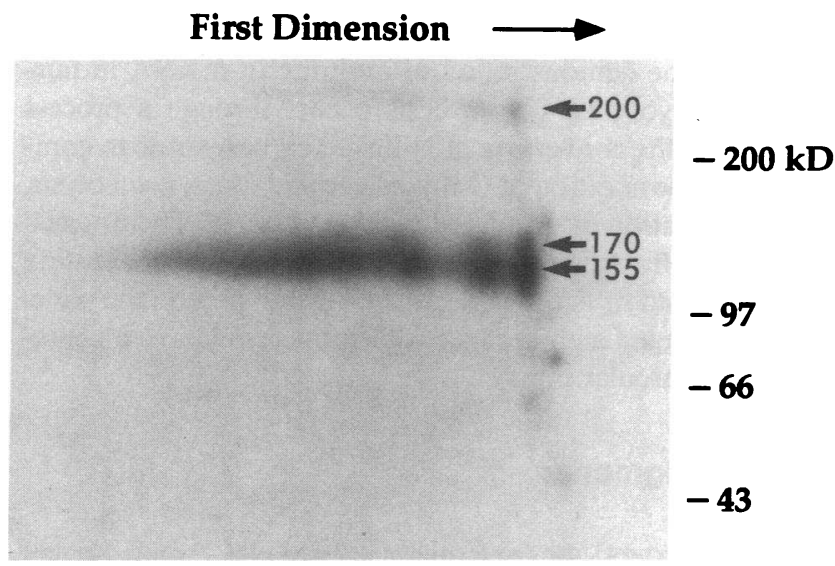

Figure 8. The composition of platelet multimerin multimers. The nature of the association of a $200-\mathrm{kD}$ protein with platelet multimerin was investigated by two-dimensional nonreduced/reduced electrophoresis. Multimerin immunoprecipitates containing the 200-kD protein were prepared using ${ }^{125}$ I surface radiolabeled activated platelets. Immunoprecipitates were separated by nonreduced agarose/acrylamide gel electrophoresis followed by reduced SDS-PAGE. The individual multimers of platelet multimerin contain mainly p-155 and p-170 subunits. However, the $200-\mathrm{kD}$ protein also was identified as a minor component of the disulfide-linked multimers. The $M_{\mathrm{r}}$ of the 200-kD subunit was determined using 5\% SDS-PAGE; anomalous migration was observed on 5-20\% gradient gel shown in this figure. munoprecipitates were prepared from Dami cell culture supernatants (18-h metabolic labelings) and from surface radiolabeled, thrombin-activated platelets. In comparison to the multimers from platelets, the constitutively secreted multimers from Dami cells were comprised mainly of the smallest multimers of the protein (Fig. 9). Two-dimensional, nonreduced/ reduced electrophoresis demonstrated that the different sized subunits of Dami cell multimerin were linked by interchain disulfide bonds.

\section{Discussion}

Multimerin is an unusually large, disulfide-linked, multimeric protein that exhibits variability in its native multimeric size, ranging from less than $450 \mathrm{kD}$ to many million Daltons (2). In our previous studies, we demonstrated that it was a unique, soluble platelet protein and demonstrated the activation-dependent nature of multimerin expression on the platelet surface (1). Further investigation demonstrated that multimerin resembles von Willebrand factor in its complex multimeric composition and that multimerin and von Willebrand factor are the two largest proteins in platelets (2). The purpose of the studies described in this report was threefold. The first studies were designed to determine the intracellular location of multimerin in platelets. The second series of investigations focused on identifying if the protein was present in megakaryocytes and whether it could be synthesized by Dami cells, a malignant megakaryocytic cell line. The third series of studies investigated the similarities and differences between the platelet and Dami cell forms of multimerin.

Previously, we have shown that multimerin is a soluble protein contained within platelets (1). Platelet activation results in a dramatic increase in the expression of multimerin on the platelet surface (1). In the current studies, we used immunoelectron microscopy to demonstrate that multimerin was contained within the $\alpha$ granules of resting platelets. Because the eccentric location of multimerin within the $\alpha$ granule resembled that of von Willebrand factor (12), dual labeling experi-

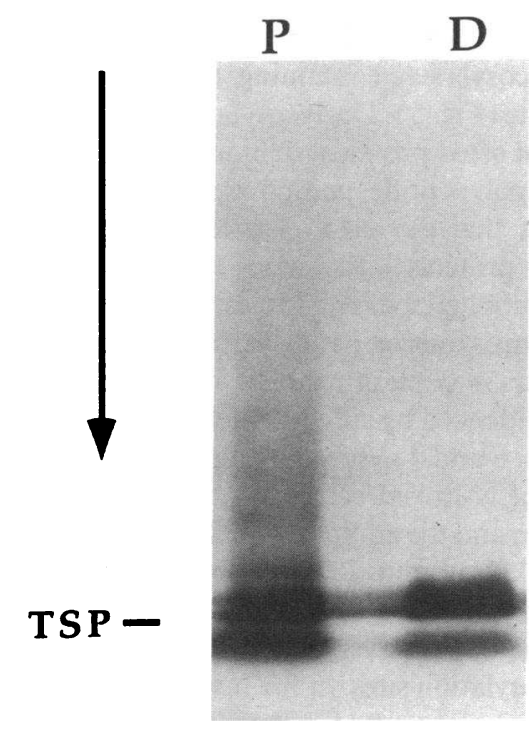

Figure 9. Comparison of the multimeric composition of platelet and Dami cell multimerin. Multimerin immunoprecipitates were prepared using ${ }^{125}$ I surface radiolabeled activated platelets $(P)$, and culture supernatant from 18-h $\left[{ }^{35}\right.$ S $]$ methionine metabolically labeled day 2 PMA-stimulated Dami cells $(D)$. Immunoprecipitates were analyzed by agarose/acrylamide gel electrophoresis. The arrow indicates the direction of migration. The position of thrombospondin

(TSP, $M_{\mathrm{r}} 450 \mathrm{kD}$ ) is shown for reference. Compared to platelet multimerin, PMA-stimulated Dami cells secrete mainly the smaller multimers of multimerin. 
ments with different sized protein A-gold were used to compare the distribution of these proteins. These studies demonstrated colocalization of multimerin and von Willebrand factor to the same region of the $\alpha$ granule (Fig. 1). In agreement with the measurable increase in multimerin on the platelet surface after platelet activation (1), multimerin was shown to redistribute to the open cannallicular system and to the external plasma membrane after activation, as well as being secreted to the extracellular medium.

The soluble nature of multimerin suggested one of two different pathways of synthesis: either endogenous biosynthesis by megakaryocytes or endocytosis of an exogenously synthesized protein. Usually, proteins that are endocytosed by megakaryocytes are present in a greater concentration in plasma than in platelets (3). In contrast, endogenously synthesized platelet proteins typically are present in greater concentration within platelets compared to plasma (3). Our previous studies failed to identify multimerin as a constituent of normal plasma (1). As a result, we postulated that multimerin was synthesized by megakaryocytes, then stored within granules.

Confirmation of endogenous biosynthesis by megakaryocytes was obtained using Dami cells, a megakaryocytic cell line. These cells synthesize a variety of platelet glycoproteins including von Willebrand factor (4). Immunohistochemistry demonstrated the presence of multimerin in normal megakaryocytes and in Dami cells (Fig. 2). Furthermore, using metabolic labeling, we demonstrated that PMA-activated Dami cells were able to synthesize multimerin (Fig. 3). The protein synthesized by the Dami cells was confirmed to be multimerin in two ways. First, two different antibodies against platelet multimerin (polyclonal and monoclonal) each immunoprecipitated the same protein. Second, Cleveland mapping demonstrated extensive peptide homology between platelet multimerin and the protein synthesized by Dami cells (Fig. 4). The Dami cell protein further resembled platelet multimerin in its soluble nature and disulfide-linked multimeric structure.

We have shown that platelet multimerin is primarily comprised of a 155-kD subunit with a smaller amount of a 170-kD subunit. Using protease digestion, peptide homology was demonstrated between these two proteins (Fig. 4). Glycosidase digestion of the p-155 and p-170 proteins demonstrated that both proteins were heavily glycosylated, containing mainly complex, N-linked carbohydrate (Fig. 5). Deglycosylation of p-155 and $\mathrm{p}-170$ yielded different sized proteins, demonstrating that p-170 contains a larger polypeptide component. Together, these observations suggest that the $\mathrm{p}-155$ protein is derived from the p-170 protein by proteolytic cleavage.

Next, pulse-chase metabolic labeling studies were used to follow the biosynthesis of multimerin. Multimerin was synthesized as a $170-\mathrm{kD}$ precursor containing high mannose, $\mathrm{N}$ linked carbohydrate, as evidenced by susceptibility to endoglycosidase $\mathrm{H}$ digestion (Figs. 6 and 7). Subsequent modification included the processing of $\mathrm{N}$-linked carbohydrate from high mannose to complex forms and the addition of O-linked carbohydrate to generate a $196-\mathrm{kD}$ subunit. Removal of all N-linked carbohydrate from the mature, $196-\mathrm{kD}$ subunit produced a 51-kD shift in apparent molecular mass, which would indicate approximately $17 \mathrm{~N}$-glycosylation sites on the multimerin precursor protein (11). Proteolysis resulted in the production of a smaller, 165-kD, secreted multimerin subunit.

In contrast to platelet multimerin, the protein synthesized and secreted by Dami cells differed in its subunit sizes. The rapid secretion of multimerin synthesized in vitro by the PMAactivated Dami cells may account for less complete proteolytic processing compared to platelet multimerin synthesized in vivo. Similar incomplete proteolysis of von Willebrand factor secreted by cultured endothelial cells has been observed (13). Additionally, the malignant Dami cells may differ from normal megakaryocytes in their expression of the glycosyltransferases involved in $\mathrm{N}$-glycosylation. This may account for the small differences in $M_{\mathrm{r}}$ observed between the Dami cell p-165 and the platelet p-170 multimerin subunits.

In contrast to platelet multimerin, which ranges in size up to many million Daltons (2), the multimerin synthesized and secreted by Dami cells contained less of the high molecular mass multimers (Fig. 9). The von Willebrand factor constitutively secreted by cultured endothelial cells also has been demonstrated to contain a predominance of the smaller multimers (13).

Our studies suggest that the platelet multimerin subunits originate from a larger precursor protein. We have occasionally observed that reduced platelet multimerin immunoprecipitates contain small quantities of a $200-\mathrm{kD}$ protein that resembles the Dami cell p-196 (2). Using two-dimensional, nonreduced/reduced electrophoresis, we demonstrated that the 200$\mathrm{kD}$ protein was a component of the disulfide-linked multimers of platelet multimerin (Fig. 8). Collectively, the evidence suggests that multimerin is synthesized both in vivo and in vitro as a larger precursor protein and that the mature, platelet multimerin undergoes proteolysis during biosynthesis and storage.

These studies indicate that multimerin is located within the $\alpha$-granules of resting platelets and redistributes to the plasma membrane and surface-connected cannalicular system following activation. Multimerin is a heavily glycosylated protein that exists as variably sized, disulfide-linked multimers of related subunits. The synthesis of multimerin by the megakaryocytic cell line supports endogenous biosynthesis by megakaryocytes. Further confirmation of a megakaryocytic origin in vivo will require the demonstration of multimerin mRNA in normal megakaryocytes. Biosynthesis occurs through a process that involves the conversion of $\mathrm{N}$-linked carbohydrate to complex forms, the addition of O-linked carbohydrate, proteolysis, and the formation of disulfide-linked multimers. The unusual repeating multimeric structure of multimerin, its localization to platelets, and its activation-induced expression on the platelet surface suggest a physiologic role in the cellular events associated with vascular injury.

\section{Acknowledgments}

The authors acknowledge the technical assistance of Yvonne Jacques, Jane Moore, Joyce Roosimagi, and Assunta Beltrano.

This study was supported by a grant from the Medical Research Council of Canada, and from the U.S. Public Health Service, HL31610.

\section{References}

1. Hayward, C. P. M., J. W. Smith, P. Horsewood, T. E. Warkentin, and J. G. Kelton. 1991. p-155, a multimeric platelet protein that is expressed on activated platelets. J. Biol. Chem. 266:7114-7120.

2. Hayward, C. P. M., T. E. Warkentin, P. Horsewood, and J. G. Kelton. 
1991. Multimerin: a series of large, disulfide-linked multimeric proteins within platelets. Blood. 77:2556-2560.

3. George, J. N. 1990. Platelet immunoglobulin G: its significance for the evaluation of thrombocytopenia and for understanding the origin of $\alpha$-granule proteins. Blood. 76:859-870.

4. Greenberg, S. M., D. S. Rosenthal, T. A. Greeley, R. Tantravahi, and R. I. Handin. 1988. Characterization of a new megakaryocytic cell line: the Dami cell. Blood. 72:1968-1977.

5. Kelton, J. G., J. W. Smith, P. Horsewood, J. R. Humbert, C. P. M. Hayward, and T. E. Warkentin. 1990. Gov ${ }^{\mathrm{a} / \mathrm{b}}$ alloantigen system on human platelets. Blood. 75:2172-2176.

6. Bainton, D. F., L. J. Miller, T. K. Kishimoto, and T. A. Springer. 1987. Leukocyte adhesion receptors are stored in peroxidase-negative granules of human neutrophils. J. Exp. Med. 166:1641-1653.

7. McEver, R. P., J. H. Beckstead, K. L. Moore, L. Marshall-Carlson, and D. F. Bainton. 1989. GMP-140, a platelet alpha-granule membrane protein is also synthesized by vascular endothelial cells and is localized in Weibel-Palade bodies. J. Clin. Invest. 84:92-99.
8. Slot, J. W., and H. J. Geuze. 1984. Gold markers for single and double immunolabelling of ultrathin cryosections. In Immunolabelling for Electron Microscopy. J. M. Polak and I. M. Varndell, editors. Elsevier Science Publishers, Oxford. p. 129

9. Johnston, G. I., A. Kurosky, and R. P. McEver. 1989. Structural and biosynthetic studies of the granule membrane protein, GMP-140, from human platelets and endothelial cells. J. Biol. Chem. 264:1816-1823.

10. Cleveland, D. W., S. G. Fischer, M. W. Kirschner, and U. K. Laemmli. 1977. Peptide mapping by limited proteolysis in sodium dodecyl sulphate and analysis by gel electrophoresis. J. Biol. Chem. 252:1102-1106.

11. Kornfeld, R., and S. Kornfeld. 1985. Assembly of asparagine-linked oligosaccharides. Annu. Rev. Biochem. 54:631-664.

12. Cramer, E. M., D. Meyer, R. le Menn, and J. Breton-Gorius. 1985. Eccentric localization of von Willebrand Factor in an internal structure of platelet $\alpha$-granule resembling that of Weibel-Palade bodies. Blood. 66:710-713.

13. Wagner, D. D., and V. J. Marder. 1983. Biosynthesis of von Willebrand protein by human endothelial cells. Identification of a large precursor polypeptide chain. J. Biol. Chem. 258:2065-2067. 